\title{
Corrections
}

Corrigendum

https://doi.org/10.13181/mji.cg.215394

Check for updates

\section{Corrigendum: A randomized clinical trial of freeze-dried amniotic membrane transplantation and conjunctival-limbal graft for pterygium excision and evaluation of conjunctival inflammation marker in tears}

Made Susiyanti, Manoa Panjaitan, Grace Wangge, Tjahjono Darminto Gondhowiardjo

Correction to: Medical Journal of Indonesia. 2020;29(4):359-65. https://doi.org/10.13181/mji.oa.203818

In the original version of this article, the affiliation of Grace Wangge was incorrectly typed as "Southeast Asian Ministers of Education Organization". It should be corrected as follows "Southeast Asian Ministers of Education Organization-Regional Center of Food and Nutrition (SEAMEO RECFON)/Pusat Kajian Gizi Regional Universitas Indonesia (PKGR UI), Jakarta, Indonesia".

\section{Erratum}

https://doi.org/10.13181/mji.er.215430

Check for updates entropion, or chronic blepharitis), ocular surface disorders ( 5 eyes with a history of Stevens-Johnson syndrome [SJS]), irradiation-induced dry eye (1 eye), allergic conjunctivitis (1 eye), and surgical trauma ( 2 eyes with phacoemulsification and pterygium avulsion). Five eyes had a history of topical steroid use, and two subjects were known to have diabetes. The median ulcer size was 3.1 (0.7-9) mm. Seventeen (34\%) ulcers were accompanied by hypopyon. Twelve eyes with perforations have a median of 1.5 (0.9-5.5) $\mathrm{mm}$ in diameter, and descemetocele was observed in six eyes. No endophthalmitis was recorded. The median duration of onset was 14 (2-120) days. Twentytwo cases developed symptoms over 2 weeks, and 15 (68.2\%) were classified as severe. The median time from the first visit to surgery was 1 (1-90) day. The median follow-up time was 11.4 (3-94.4) weeks." Also, the first sentence of second paragraph of results on page 382 (right column, line 1 from top of paragraph) should begin with "Microorganisms were found in cultures from 25 eyes, dominated by Gram-positive cocci (Table 2)."

\section{Erratum: Amniotic membrane transplantation for infectious corneal ulcer treatment: a cohort retrospective study}

Vega Casalita, Rina La Distia Nora, Lukman Edwar, Made Susiyanti, Ratna Sitompul

Correction to: Medical Journal of Indonesia. 2020;29(4):379-85. https://doi.org/10.13181/mji.oa.203849

In the original version of this article, some sentences in the first and second paragraphs of results were missing. The last sentence of first paragraph of results on page 381 (right column, line 8 from top of paragraph) should end with "The most common local predisposing factors for corneal ulcer were nonsurgical trauma (22 eyes with metal cutting fragments, foreign body particles, and nail or wire scratches), followed by contact lens use (14 eyes), eyelid function disorders ( 5 eyes with lagophthalmos, 